\title{
Oscillatory and periodic solutions in alternately advanced and delayed differential equations
}

\author{
KuO-ShOu CHIU and MANUEL PINTO
}

\begin{abstract}
.
We examine scalar differential equations with a general piecewise constant argument (DEPCAG). It is shown that the argument deviation generates, under certain conditions, oscillations of the solutions, which is an impossible phenomenon for the corresponding equation without the argument deviations. Criteria for existence of periodic solutions of such equations are discussed.
\end{abstract}

Acknowledgements. The first author's research was supported by FIBE 01-12 DIUMCE and the second author's research was supported by FONDECYT 1120709.

\section{REFERENCES}

[1] Aftabizadeh, A. R. and Wiener, J., Oscillatory properties of first order linear functional differential equations, Appl. Anal., 20 (1985), 165-187

[2] Aftabizadeh, A. R. and Wiener, J., Oscillatory and periodic solutions of an equation alternately of retarded and advanced type, Appl. Anal., 23 (1986), 219-231

[3] Akhmet, M. U., Integral manifolds of differential equations with piecewise constant argument of generalized type, Nonlinear Anal., TMA, 66 (2007) 367-383

[4] Bereketoglu, H., Seyhan, G. and Karakoc, F., On a second order differential equation with piecewise constant mixed arguments, Carpathian J. Math., 27 (2011), No. 1, 1-12

[5] Cooke, K. L. and Wiener, J., An equation alternately of retarded and advanced type, Proc. Amer. Math. Soc., 99 (1987), 726-732

[6] Chiu, Kuo-Shou and Pinto, M., Variation of parameters formula and Gronwall inequality for differential equations with a general piecewise constant argument, Acta Math. Appl. Sin. Engl. Ser., 27, (2011), No. 4, 561-568

[7] Chiu, Kuo-Shou and Pinto, M., Periodic solutions of differential equations with a general piecewise constant argument and applications, E. J. Qualitative Theory of Diff. Equ., 46 (2010), 1-19

[8] Chiu, Kuo-Shou and Pinto, M., Stability of periodic solutions for neural networks with a general piecewise constant argument, First Joint International Meeting AMS-SOMACHI, December, 15-18, (2010), Pucón, Chile

[9] Chiu, Kuo-Shou and Pinto, M., Green's function for periodic solutions in alternately advanced and delayed differential systems, LXXIX Encuentro de SOMACHI, November, 5-7, (2009), Olmué, Chile

[10] Dai, L., Nonlinear Dynamics of Piecewise of Constant Systems and Implementation of Piecewise Constants Arguments, World Scientific, Singapore, 2008

[11] Karakoc, F., Bereketoglu, H. and Seyhan, G., Oscillatory and periodic solutions of impulsive differential equations with piecewise constant argument, Acta Appl. Math., 110 (2009), No. 1, 499-510

[12] Ladde, G. S., Lakshmikantham, V. and Zhang, B. G., Oscillation Theory of Differential Equations with Deviating Arguments, Dekker, New York, 1987

[13] Pinto, M., Asymptotic equivalence of nonlinear and quasilinear differential equations with piecewise constant arguments, Math. Comput. Modelling, 49 (2009), 1750-1758

[14] Pinto, M., Cauchy and Green matrices type and stability in alternately advanced and delayed differential systems, J. Difference of Eqs. Appl., 17 (2011), No. 2, 235-254

Received: 17.02.2012; In revised form: 16.11.2012; Accepted: 12.12 .2012

2010 Mathematics Subject Classification. 34A36, 34K11, 34K13, 35M10.

Key words and phrases. Piecewise constant arguments, oscillation, nonoscillation, periodic solutions, hybrid equations.

Corresponding author: Kuo-Shou Chiu; kschiu@umce.cl 
[15] Rodrigues, I. W., Systems of differential equations of alternately retarded and advanced type, J. Math. Anal. Appl., 209 (1997), No. 1, 180-190

[16] Seifert, G., Almost periodic solutions of certain differential equations with piecewise constant delays and almost periodic time dependence, J. Differential Equations, 164 (2000), 451-458

[17] Shah, S. M. and Wiener, J., Advanced differential equations with piecewise constant argument deviations, Int. J. Math. Math. Sci., 6 (1983), 243-270

[18] Wang, Gen-Qiang and Cheng, Sui-Sun, Periodic solutions of discrete Rayleigh equations with deviating arguments, Taiwanese J. Math., 13 (2009), No. (6B) 2051-2067

[19] Wang, Gen-Qiang and Cheng, Sui-Sun, Existence and uniqueness of periodic solutions for a second-order nonlinear differential equation with piecewise constant argument, Int. J. Math. Math. Sci., 2009, Art. ID 950797

[20] Wang, Y. and Yan, J., Oscillation of a differential equation with fractional delay and piecewise constant arguments, Comput. Math. Appl., 52 (2006), 1099-1106

[21] Wiener, J., Generalized Solutions of Functional Differential Equations, World Scientific, Singapore, 1993

[22] Wiener, J. and Aftabizadeh, A. R., Differential equations alternately of retarded and advanced type, J. Math. Anal. Appl., 129 (1988), 243-255

[23] Wiener, J. and Lakshmikantham, V., A damped oscillator with piecewise constant time delay, Nonlinear Stud., 7 (2000), 78-84

DEPARTAMENTO DE MATEMÁticA

FACULTAD DE CIENCIAS BÁSICAS

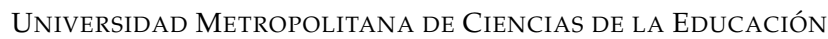

SANTIAGO, CHILE.

E-mail address: kschiu@umce.cl

Departamento de MATEMÁticas

FACUlTAD DE CiENCIAS

UNIVERSIDAD DE CHILE

SANTIAGO, CHILE.

E-mail address: pintoj@uchile.cl 